\title{
Smart city services: an empirical analysis of citizen preferences
}

\author{
Bernd W. Wirtz ${ }^{1}$ (D) Marcel Becker $^{1} \cdot$ Florian W. Schmidt $^{1}$
}

Accepted: 6 September 2021 / Published online: 12 October 2021

(c) The Author(s) 2021

\begin{abstract}
In times of increasing urbanization worldwide, smart city management is becoming increasingly important. In this regard, successful implementation requires not only the creation of technological foundations but also, in particular, the inclusion and engagement of the citizens of the respective "smart city" (SC). Despite their recognized importance, knowledge concerning their needs and preferences is currently still rather limited. By surveying 906 citizens of a SC, this study provides comprehensive insights into the preference and relevance structure of digital SC services from a citizen perspective. To compare and contrast, the findings are finally crossreferenced with survey results from public officials.
\end{abstract}

Keywords Smart city $\cdot$ Digital public services $\cdot$ Citizen preferences $\cdot$ Public officials' assessments · Valuation discrepancy

\section{Introduction}

In the course of the worldwide trend of increasing and rapidly advancing urbanization, new and innovative planning and governance approaches in the form of smart city (SC) concepts are increasingly gaining in importance (Albino et al., 2015; Cardullo \& Kitchin, 2019). The creation and implementation of SC concepts is based in particular on the integration and application of information and communication technologies (ICTs) in combination with the Internet of Things (IoT) and smart data in order to refine public services and make them accessible to the general

Bernd W. Wirtz

1s-wirtz@uni-speyer.de

Marcel Becker

mbecker@uni-speyer.de

Florian W. Schmidt

schmidt@uni-speyer.de

1 Chair for Information and Communication Management, German University of Administrative Sciences Speyer, Freiherr-vom-Stein-Str. 2, 67346 Speyer, Germany 
public (Ullah et al., 2020; Yigitcanlar et al., 2021). The objectives and potential added values pursued by this are manifold. These include not only improving efficiencies in public administration and supporting economic growth, but also complying with sustainability aspects and promoting the general quality of life of citizens in the relevant urban areas (Pereira et al., 2018; Vanolo, 2016).

While the first mentioned objectives concerning the improvement of public administrations' efficiency and economic growth are relatively easy to measure by means of defined value targets and achieved results, this is more complicated when it comes to the measurement of sustainability aspects and in particular with regard to the promotion and enhancement of the general quality of life of citizens (Ahvenniemi et al., 2017). Nevertheless, the added value and the actual "smartness" in city management is significantly related to the involvement of external stakeholders and, in particular, the citizens as the largest stakeholder group (Woetzel et al., 2018).

Because of the generally acknowledged importance of citizens in context of SC conceptualization and overall project success, a couple of dedicated research efforts focusing on citizens in the SC context study already exist. For instance, Johnson et al. (2020) illustrate the extent to which citizens can interact with their respective $\mathrm{SC}$ and how these interactions present themselves on a citizen-centric level, in order to be able to better contextualize the big picture of the SC. In addition, Simonofski et al. (2021) and Gohari et al. (2020), among others, present the different needs of citizens in locally diverse SC projects and show that long-term successful smart cities seek to specifically address their respective unique environments with their associated local contexts and relationships.

However, a number of further SC research studies have already shown that the citizen-centric development of SC concepts and services remains frequently inadequate. As a result, many SC projects as yet are still frequently conceptualized and developed primarily from the point of view of public institutions and their representatives, without sufficient integration of citizens in those processes taking place (Kitchin, 2015; Shelton \& Lodato, 2019).

Thus, in order to make smart cities even more sustainable and successful on a broad scale in the future, ,[i]t is [generally] necessary to motivate investments and policies on topics related to citizens' participation in government decisions “ (Oliveira et al., 2020, p. 15), whereby in particular the whole set of needs regarding " [...] all demographies and neighborhoods should be on the agenda when cities choose which programs to pursue" (Woetzel et al., 2018, p. 16).

Against the background of the central role of citizens in the SC context and in support for future SC developments, by means of an empirical survey, this study aims to identify and classify those SC services that are considered to be important by citizens and, accordingly, are expected to be used in the future. In comparison to the public sector's estimations, two central research questions subsequently emerge: What services are of particular relevance to citizens within the SC context? To what extent do the opinions on the importance of SC services differ between citizens and public officials?

To elaborate answers to these questions and to empirically confirm them, this study proceeds as follows: For general orientation and as a basis for the subsequent empirical investigation, section two first presents relevant citizen-centered SC 
literature before section three briefly and succinctly presents the conceptual framework of how and by which service domains citizens interact in the SC context. Next, Sect. 4 describes the methodology of the empirical study regarding citizens and public officials and presents the results accordingly. Finally, the central results are discussed in section five and conclusions for science and practice are derived.

\section{State of research}

The potentially far-reaching added values which result from the development and implementation of SC projects often find their origin in increasing digitization of public sector services and the combination of new technologies and the processing of large and diverse amounts of data (Ullah et al., 2020; Yigitcanlar et al., 2021). As a result, the underlying research on SC development until recently focused on investigating technological aspects and issues, so that the technological development of urban infrastructures was for a long time considered to be the central success factor for the entire path towards an actually "smart" city management (Chourabi et al., 2012).

However, although the necessity and importance of those technological aspects for the development of SC projects is undisputed in principle, there is an increasing number of contributions within SC research that point to the need for more citizen-centered research (Hollands, 2015; Joss et al., 2017; Kitchin, 2015; Shelton \& Lodato, 2019). In this connection, a distinction can be made between two significant research streams, both of which deal with the same core topic of smart city management, but each of which approaches it from a different perspective. The first, primarily frequented technology-oriented research stream has been complemented by another approach, the citizen or people-oriented research stream (Marrone \& Hammerle, 2018; Mora et al., 2017), focusing on the need for technological adaptation and the creation of social acceptance and engagement regarding SC services among stakeholder groups (Angelidou, 2015).

While the technological as well as data-specific aspects form the basis for SC development, the especially important role as the largest stakeholder and user group also indicates ,that citizen's inclusion in developing smart services is key to improve the attractiveness and success of the smart city " (Abella et al., 2019, p. 4). The implication that achieving sustainable SC project success requires a comprehensive consideration of the multifaceted requirements of the population and the integration of affected citizens, if possible, already during the conception phase of SC projects, is today widely acknowledged in the research community (Cardullo \& Kitchin, 2019; Oliveira et al., 2020; Woetzel et al., 2018). If such an integration and joint cooperation between the city and its habitants fail to materialize ,there can be no real active citizenship participation, and consequently it cannot [result in] a real intelligent city" (Zubizarreta et al., 2016, p. 1).

In order to classify which requirements and expectations citizens have regarding the general SC design and its specific services, several studies were already carried out by surveying citizens as the central point of reference. For example, within their citizen-centric empirical study, Lamberti et al. (2014) outline, among 
other things, in which areas the main motivators for comprehensive and sustained engagement within the SC context lie. They conclude that, in particular, the realization of potential savings in terms of monetary and time-related cost factors that can be offered through SC services has a positive impact on citizens' perceptions and participation.

Further empirical studies, for example by Vidiasova et al. (2018), are also primarily dedicated to the citizen side. Drawing on a content analysis and a separate survey, it shows that although the topic of SC is often discussed with a focus on technological aspects, this fact has neither a strong positive nor a negative influence on citizens' interest in SC concepts. The still existing interest and willingness of citizens' to participate in SC projects identified in their research implicitly shows the great potentials that might arise in case of a corresponding citizenoriented communication and design of SC services. Some other empirical studies also deal with the core expectations of citizens in connection with SC services or their contribution to increasing quality of life (Biagi et al., 2018), the determinants for defining citizen satisfaction (Macke et al., 2019), and the evaluation of preferred SC domains from the citizen's perspective (Ji et al., 2021).

Nonetheless, there is potential for further people-oriented research as, "[...] although SC literature emphasizes the necessity to design SCs in a user-oriented manner aligning its range of public smart services to urban demand, research has not examined the preferences of SC user to a sufficient extent" (Wirtz et al., 2021, p. 313).

For example, a commonly used approach to investigate citizens' preferences regarding public smart service offerings and their behavioral intention to use specific SC services is to study behavioral patterns and attitudes of small samples, such as Wirtz et al. (2021) conducted through a lead user survey. Even though empirical research with a small sample size, if appropriately heterogeneous and contrasted, can yield informative findings that can in principle be generalized to the whole, there is also a risk of arriving at biased results (Patton, 2015; von Hippel, 1986).

Despite the studies presented as examples and regardless of methodological aspects, there are still relatively few empirical SC studies overall that focus on citizens' preferences and perceptions of individual SC services within the peopleoriented stream, which is because the research field is still developing. An even smaller number of studies compare the preferences and attitudes of citizens with the corresponding attitudes and opinions of responsible public officials, who are actually in charge of conceptualizing and designing SC projects. However, those studies focus less on examining the perceived importance of and preferences for digital services within a SC in particular, and more on differences in perceptions among SC components and overall participatory development (Gohari et al., 2020; Lytras et al., 2019; Vidiasova \& Cronemberger, 2020). Given the mentioned importance of SC services for communication, coordination and goal achievement in the overall SC context, a dedicated survey of citizens and public officials followed by a corresponding comparison may provide new valuable insights into the different perceptions of citizens on the demand side and public officials on the supply side. 


\section{Smart city service framework}

Within people-oriented SC research, one of the most important investigation areas is to determine which overall concepts and service domains are most suitable for integrating citizens as comprehensively as possible into SC projects (Abella et al., 2019; Cardullo \& Kitchin, 2019). However, for orientation and adequate placement of empirical research, it is necessary to understand the underlying conceptual structure of a SC and to understand by means of which SC services citizens interact within the SC context as a whole. The SC Service Provision Framework (Fig. 1) of Wirtz et al. (2021) reflects relevant theoretical reference points and components and may serve as a conceptual basis for this research.

As mentioned, SC services are closely linked to IoT capabilities and their combination with modern ICTs and smart data (Chourabi et al., 2012; Ullah et al., 2020). The technological foundation of IoT services and consequently also of SC services can be structured into three central components, namely the data centers, internet and network infrastructures, and the endpoint devices which have to be connected accordingly (Wirtz et al., 2019). Within SC context, public urban data centers
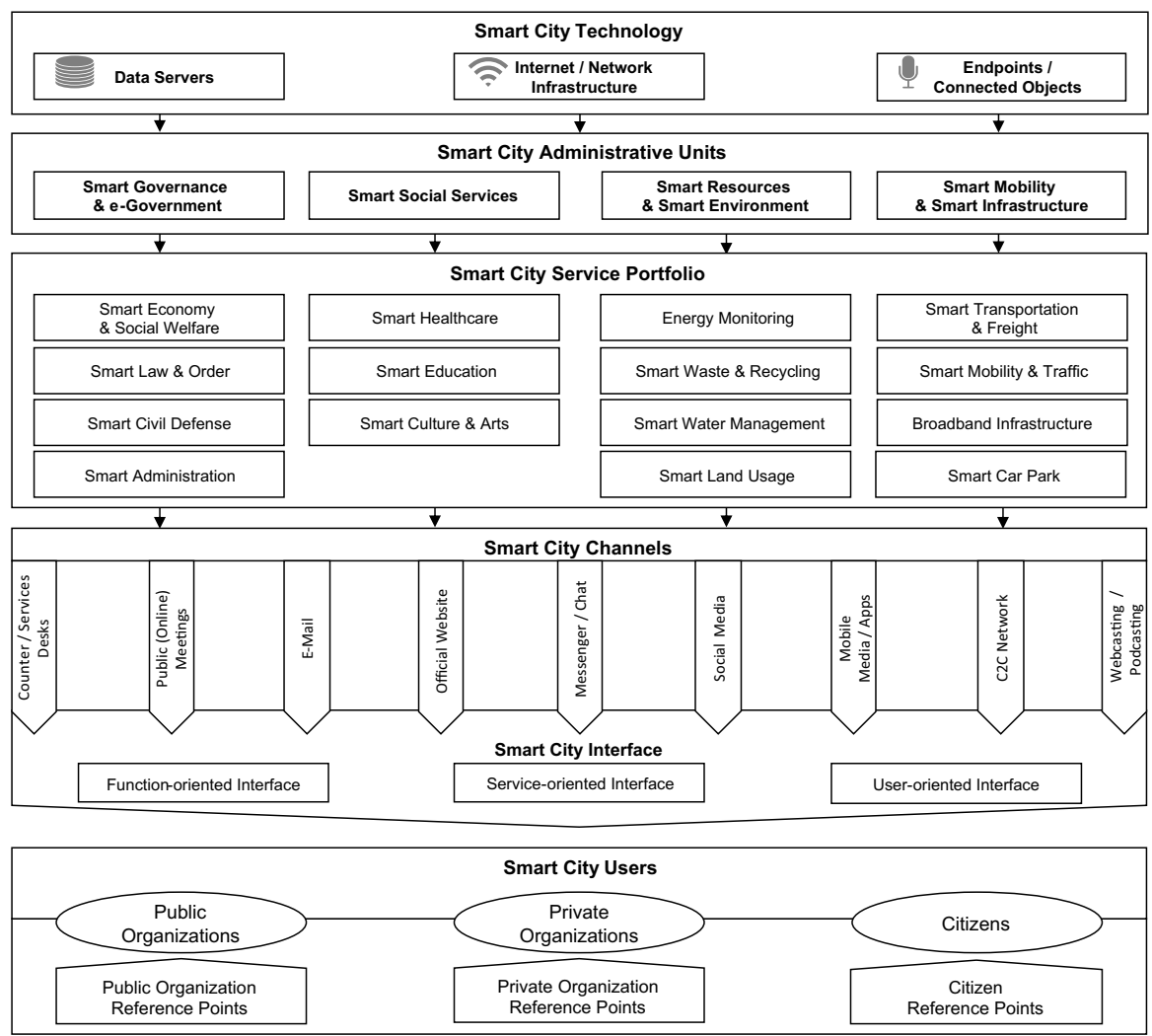

Fig. 1 SC Service Provision Framework (Wirtz et al., 2021) 
receive, process and store relevant data, which is transferred via secure internet and network infrastructures to the corresponding endpoint devices, which serve as service interface and connector, and vice versa (Heaton \& Parlikad, 2019; Vanolo, 2016).

Related SC services can be assigned to different overarching service branches respectively administrative units depending on their content and reference points. Paying attention to different approaches to classify administrative units concerning SC management (Gil-Garcia et al., 2015; Neirotti et al., 2014), Wirtz et al. (2020) identified a total of four central administrative units, into which multiple dedicated SC service domains and individual SC services can be grouped. These administrative units are (1) Smart Governance \& e-Government, (2) Smart Social Services, (3) Smart Resources \& Smart Environment, and (4) Smart Mobility \& Smart Infrastructure.

Specific SC service domains can be assigned to the four administrative units forming the SC service portfolio. For further research efforts, this has the advantage that investigations can be conducted either generally (i.e., based on the overarching administrative units) or more decisively (i.e., based on the individual SC services or service domains), depending on the research objective (Wirtz et al., 2021). A mix of communication channels and interaction methods can be determined for specific target groups, focusing on the users to be communicated or interacted with in the individual SC project (Anttiroiko et al., 2014).

Based on this, the design of the survey can be derived hereafter, intended to investigate which SC services are particularly relevant for citizens and how their opinion differs from public officials' assessment.

\section{Methodology and empirical results}

\section{Methodology and data collection}

In order to generate comprehensive insights into citizens' preferences and attitudes regarding the relevance of SC services, a web-survey was conducted among residents of a mid-sized German city.

The reasons for deciding on the method of a web-survey were in particular the fact that this methodical procedure can increase both the basic willingness to participate and the response rate if the design is appropriately adequate (Christensen et al., 2020; Zikmund et al., 2013). Although no incentives were offered for answering the standardized questions in the questionnaire in order to keep any potential response biases low, a high level of participation in the web survey could be recorded over the relatively short period of four weeks from January to February 2021.

A further reason was that such an approach prevents potential influence from an interviewer which can lead to distorted results (Callegaro et al., 2015). When examining the substantiveness of the sample for other potential biases, such as nonresponse bias (Groves \& Peytcheva, 2008), the repeated significance testing of variances between early and late responses did not reveal any noticeable findings in the form of nonresponse bias with respect to the later final sample. 
During the survey period between January and February 2021, a total of 906 valid questionnaires were collected, out of which 417 questionnaires were answered by female respondents and 489 by male respondents. The age structure of the sample is shown in Fig. 2 and demonstrates participation along all age groups, whereby a majority of the respondents is between 35 and 64 years old.

In terms of personal educational attainment, 28.8 percent of survey participants reported having a secondary school certificate, 17.4 percent had a high school diploma, 44.7 percent had a college degree, and 9.1 percent had other educational qualification. Regarding the general intensity of internet usage, a minority of 5.1 percent of respondents reported using the internet for less than one hour on average per week, while a majority of respondents (39.2 percent) uses the internet for more than four hours per week. Altogether, this addresses the requirement stated by Woetzel et al. (2018) to consider demographic diversity when studying in the SC context.

Based on previous knowledge from SC research in general and the conceptual template of the SC service provision framework by Wirtz et al. (2021) in particular, a total of 173 digital services out of the SC context were submitted for evaluation within the citizen web-survey. These in turn can be classified into 14 respective SC service domains and four superordinate administrative units. The individual SC services were rated accordingly by the respondents in terms of relevance of each individual service using a 5-point Likert scale. In that context, the scale value 1 marked a "very low" relevance, whereas the scale value 5 marked a "very high" relevance. These evaluations can be used to identify corresponding preferences and derive insights about which individual SC services are in demand or considered to be important and are therefore likely to be used more intensively.

Since people-oriented smart city management is still a relatively new phenomenon, in addition to the survey of citizens, 10 public officials of the same city were

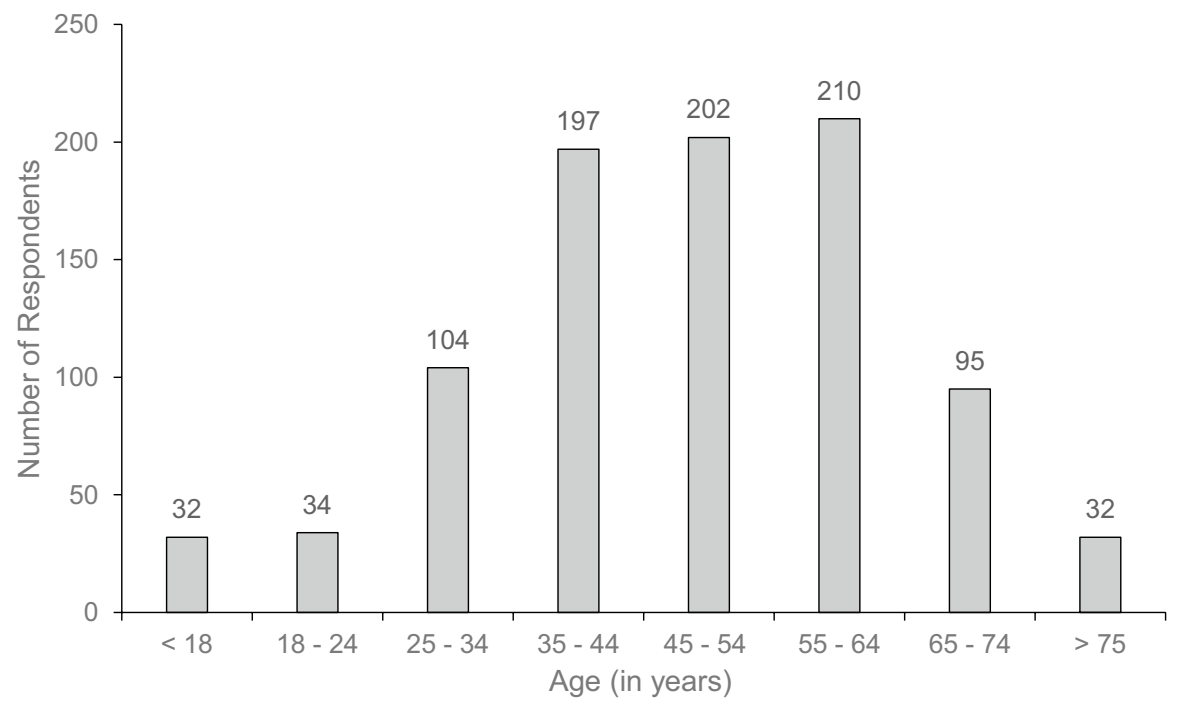

Fig. 2 Age Structure of the Sample 
asked to rate the same set of SC services in terms of their relevance within the overall SC context. This makes it possible to illuminate not only the perspective of the demand side (the citizens), but also the perspective of the supply side (the city and its public officials), and to compare the opinions and evaluations accordingly in order to point out eventual differences.

\section{Empirical results}

In the course of data analysis of the citizens' survey, the 173 digital services were examined with regard to their assessed relevance from the citizens' point of view. For this purpose, citizens were requested as part of the web survey to rate the relevance of each digital service separately for themselves.

In order to allow an initial, general assessment and comparability on the basis of the four superordinate administrative units, the 173 individual services were first assigned to the corresponding units after citizens' evaluation had been completed. The administrative unit that is rated the most relevant in the overall SC context by citizens, on average, is the one of "Smart Social Services". Given a weighted scale value of 3.69, the entire unit's digital services reflect a tendency toward being considered to be highly relevant. The situation is quite similar for the administrative unit "Smart Mobility \& Smart Infrastructure", which also reflects a fairly high relevance from the citizens' perspective with a weighted scale value of 3.67.

Despite the fact that the two remaining administrative units "Smart Resources \& Smart Environment" and "Smart Governance \& E-Government" still have scale values above 3.0, they fall back a little in the aggregated relevance rating with values of 3.45 and 3.34 respectively. However, from this top-down view, it can be concluded that, on balance, none of the four superordinate administrative units has a low or even very low relevance for citizens. This is illustrated accordingly in Fig. 3. Accordingly, no unit should be excluded from further observation.

Insights can also be derived from a little more differentiated consideration of the 14 SC service domains. For instance, there are also no groupings of services among the SC service domains that are given an average value of less than 3.0 by the citizens regarding their relevance. However, the ratings for the different SC subdomains vary considerably, ranging from a minimum of 3.03 to a maximum of 4.05 , reflecting a much wider range of relevance perceptions in comparison (see Fig. 4). This demonstrates that citizens consider some contents of individual service groups to be more important in relation to others, a finding that may be of added value concerning future focus on expansion of SC services, for example.

It is also noticeable that none of the superordinate administrative units exclusively consists of either relevant or less relevant SC service domains, which underlines the diversity of the SC context (cf. Appendix).

All listed SC service domains are functional subdomains of a SC that represent different tasks and demands of a SC and its stakeholders. The SC service domain that achieves the highest rating with 4.05 based on the aggregation of the relevant individual services is the "Broadband Infrastructure". This includes digital services such as a city-wide, publicly accessible WLAN network and the comprehensive 
4

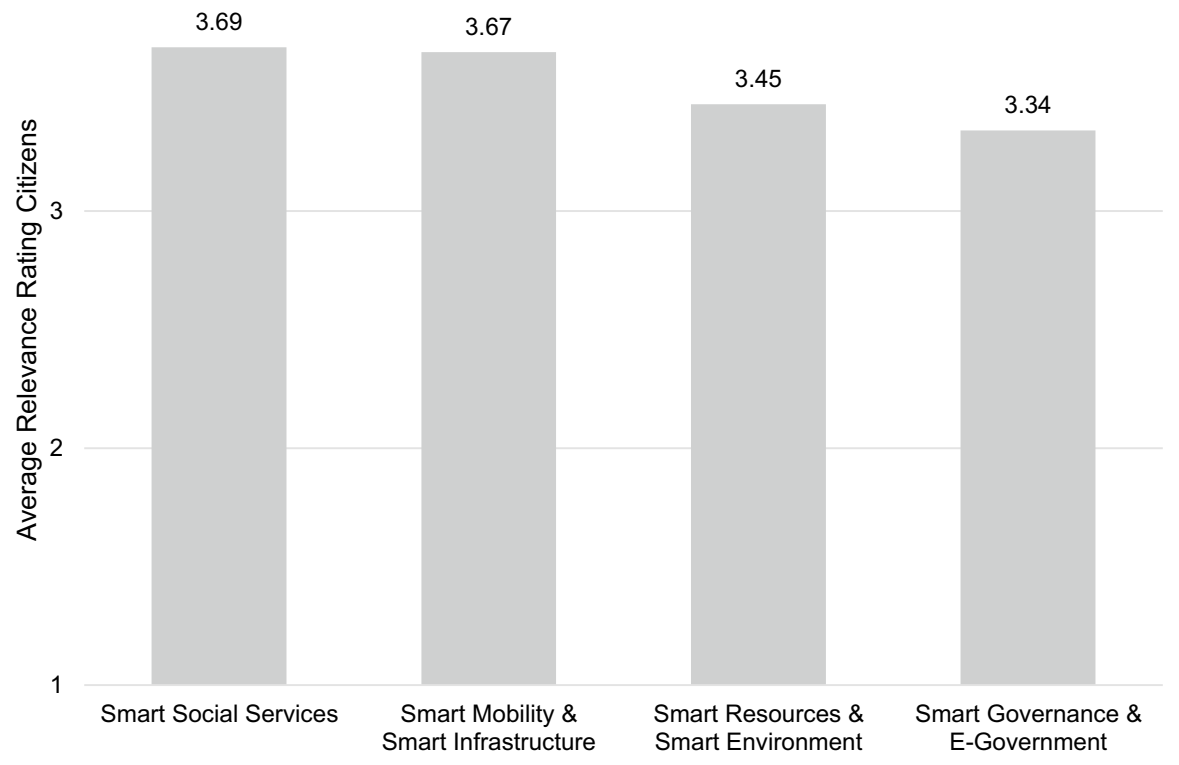

Relevance Rating | $1=$ very low $\mid 2=$ low $\mid 3=$ medium $\mid 4=$ high $\mid 5=$ very high

Fig. 3 Average Relevance Rating of SC Service Branches/Administrative Units (assignment of subgroups see appendix)

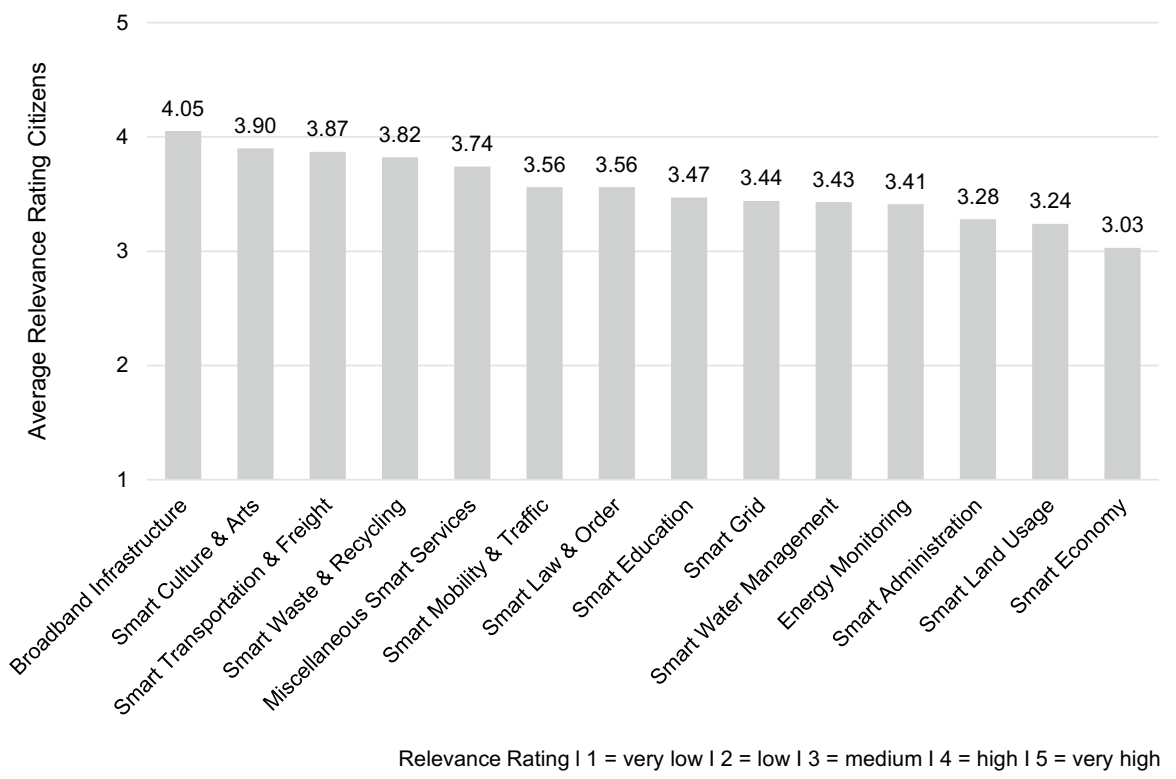

Fig. 4 Average Relevance Rating of SC Service Domains 
expansion of the fiber optic and broadband internet structure. In second and third place among the SC service domains are "Smart Culture \& Arts" and "Smart Transportation \& Freight" with respective scores of 3.90 and 3.87 on average. The "Smart Culture \& Arts" domain includes services such as a digital event database, a digital real-time messaging system for cultural events, a digital ticket booking system for cultural events, a digital culture-news platform and a digital cultural property register. "Smart Culture" is therefore a subdomain of SC that depicts the cultural and artistic tasks in the context of digital urban development. The "Smart Transportation \& Freight" domain includes individual services such as an interactive public transport timetable or real-time data-based route planning solutions for public transport.

These ratings largely correspond with the findings from looking at the superordinate administrative units, as the top 3 SC service domains can be assigned to the first and second ranked administrative units. In connection with the consideration of the next relevant SC service domains "Smart Waste \& Recycling" (3.82) and "Miscellaneous Smart Services" (3.74), it is also noticeable that all administrative units are represented within the top 5 SC service domains, which again reflects the generally multi-layered structure of relevance in the SC context. Within the scope of "Smart Waste \& Recycling", individual services such as a digital schedule for waste collections or an online information portal for correct waste disposal and recycling are being addressed. The "Miscellaneous Smart Services" domain, for its part, comprises services that cannot be clearly assigned to any other SC service domain, such as the establishment of a general, digital problem reporting system.

Based on the relevance ratings, the further development and improvement of SC services from the top 5 service domains is of particular importance.

Within the SC service domain "Smart Mobility \& Traffic", individual services like a digital road works information system, a digital parking guidance system or a digital parking exchange system have been submitted for evaluation. Individual services relating to the "Smart Law \& Order" domain include, for example, a digital payment system for parking and traffic offenses or a digital legal information portal. With an average rating of 3.56 for each, the "Smart Mobility \& Traffic" and "Smart Law \& Order" service domains also tend to be highly relevant. All in all, seven out of the $14 \mathrm{SC}$ service domains have a high or at least a tendency to high relevance rating.

In contrast, the SC service domains of the other half tend to have medium relevance ratings. The average rating of 3.47 for the "Smart Education" service domain is composed of ratings for individual services, like a public education database or an interactive information portal for pre-schools and schools. "Smart Grid" has an average rating of 3.44 and includes, among other things, services in the field of electromobility, such as the expansion of charging infrastructure and its intelligent management. "Smart Water Management" (3.43) includes services such as digital information portals on water quality and digital complaint systems for water-related issues, while "Energy Monitoring" (3.41) includes services such as digitally controlled and energy-efficient street lighting or an interactive suggestion system for energy-efficient solutions for public spaces.

The three SC service domains with the lowest average relevance rating from a citizen's perspective are the areas of "Smart Administration" (3.28), "Smart Land 
Usage" (3.24) and "Smart Economy" (3.03). As part of the "Smart Administration" domain, a number of services relating to public administration in the context of increasing digitization were surveyed, such as digital solutions for submitting various administrative applications or generally smarter communication options with public offices and authorities. "Smart Land Usage" includes services like digital information portals on environmental and nature conservation data as well as digital approaches concerning planning and approval of development plans and corresponding building plots. The domain "Smart Economy" consists of services, as for example digital support programs for start-ups as well as public digital tendering systems.

In addition to the analysis of the relevance ratings from the citizen's perspective, further valuable insights can be generated on the basis of the relevance ratings regarding the same digital services by the public officials. When comparing the assessments of citizens with those of public officials, it becomes apparent that the assessments generally differ from each other considerably when looking at the level of the superordinate administrative units (see Fig. 5). In this context, the administrative units "Smart Social Services" (0.55) and "Smart Resources \& Smart Environment" (0.56) exhibit the lowest valuation discrepancies.

While some variations in ratings are quite normal and to a certain extent attributable to differing attitudes as well as opinions of the respondents, this comparison

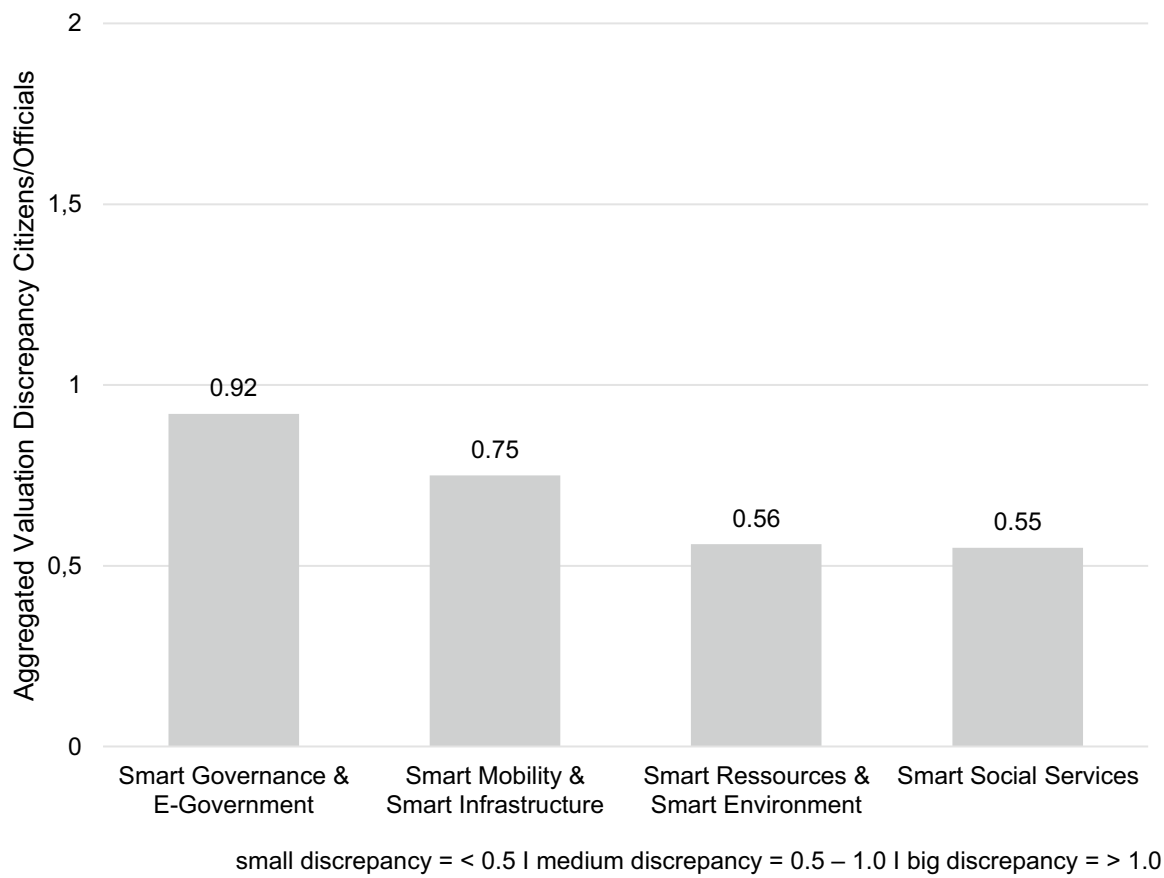

Fig. 5 Average Valuation Discrepancy regarding Administrative Units between Citizens/Officials (Assignment of subgroups see appendix) 
nevertheless reveals that the supply and demand sides are still relatively far from a uniform picture of opinion.

This becomes even more evident when the valuation discrepancies concerning the administrative units "Smart Mobility \& Smart Infrastructure" (0.75) and "Smart Governance \& E-Government" are added to comparison, which in the case of the latter even amounts to almost a whole scale point with an average of 0.92 . Accordingly, there is great potential to be found in this superordinate group in particular for aligning mutual expectations and opinions.

Not surprisingly, the situation is very similar for the separate SC service domains, as depicted in Fig. 6. While there are some domains, such as "Smart Economy" (0.39) or "Smart Water Management" (0.41), for which the valuation discrepancy is rather low, there are also domains with partially sensitive discrepancies. With valuation discrepancies of over 1.0 each, especially the domains "Smart Grid" (1.56) and "Energy Monitoring" (1.05) stand out. Specifically for these domains as well as the following ones "Smart Administration" (0.96) and "Smart Law \& Order" (0.94), the need to align the supply side more closely with the demand side, which has already been called for in the literature, appears to be confirmed.

Moreover, as part of the comparative analysis, it can be seen that the relevance ratings of public officials are higher than the relevance ratings of citizens in almost 80 percent of cases across all SC services surveyed (see Fig. 7). While this trend extends across all superordinate administrative units, it is particularly pronounced in the area of "Smart Governance \& eGovernment", so that for every

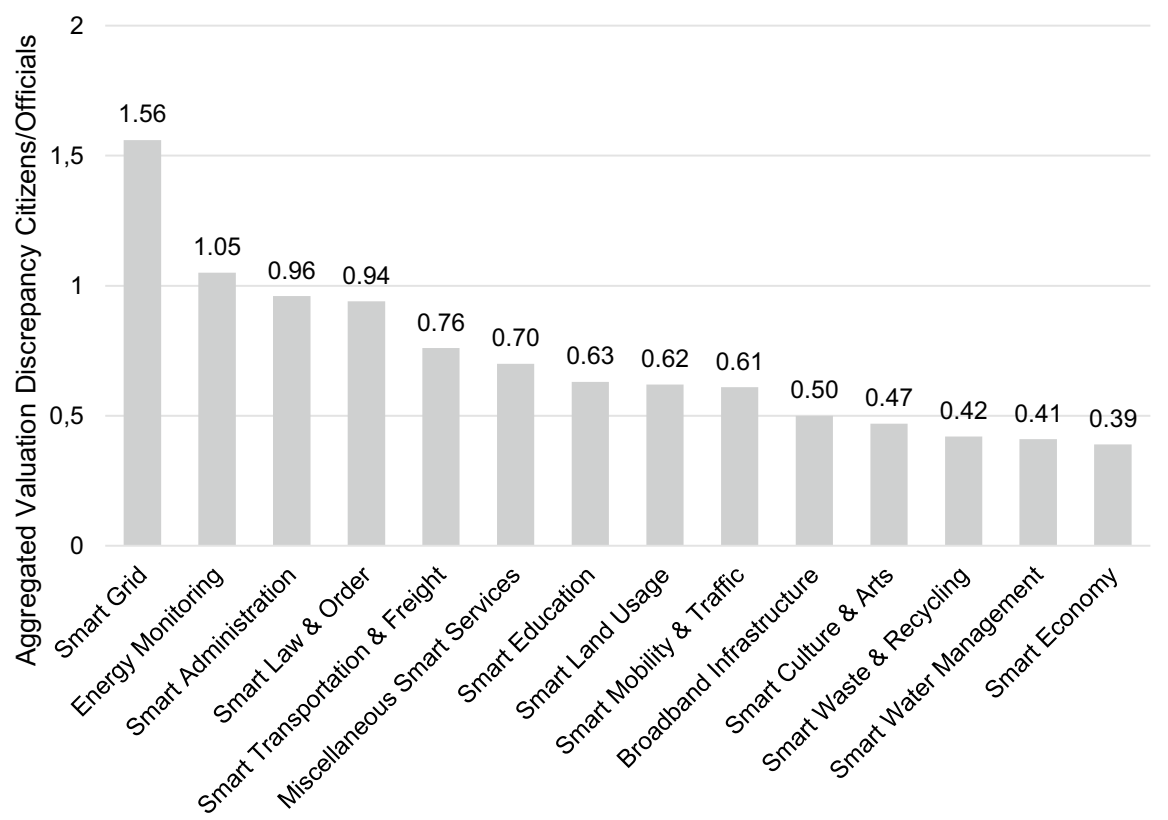

small discrepancy $=<0.5 \mathrm{I}$ medium discrepancy $=0.5-1.0 \mathrm{I}$ big discrepancy $=>1.0$

Fig. 6 Average Valuation Discrepancy regarding SC Service Domains between Citizens/Officials 
$1: 3,78$

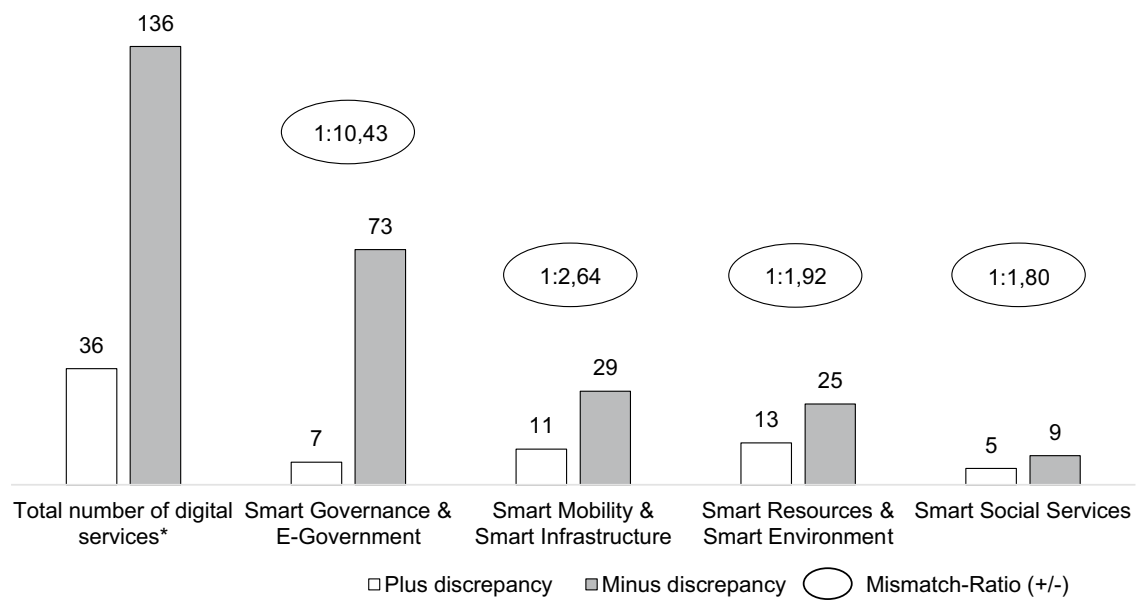

Plus discrepancy $=$ Citizens' relevance rating exceeds public officials' rating Minus discrepancy $=$ Citizens' relevance rating undercuts public officials' rating

Fig. 7 Mismatch-Ratio regarding Relevance Rating between Citizens/Officials

service for which the relevance rating of citizens exceeds those of public officials, there are approximately 10 services for which the assessment is exactly the opposite.

All in all, the public officials generally attribute greater relevance to the SC services they provide than can be confirmed by the evaluation results from the citizens representing the external stakeholders concerned. Even though this does not necessarily result in negative consequences for an SC project as a whole, it nevertheless reveals once again the considerable potential that can be realized in terms of aligning the supply and demand sides to create a SC that meets the needs of its key stakeholders as closely as possible.

\section{Discussion and conclusion}

Since one of the key success parameters within SC management is the fundamental improvement of the quality of life of its residents, the sustainable success of a SC project depends in large part on the comprehensive involvement and continuous commitment of its citizens. To achieve such an engagement and commitment, it is required to adapt and synchronize SC services, which function as central elements of communication and interaction, to the expectations and preferences of citizens. To identify and analyze those expectations and preferences of citizens with the help of a large-scale online citizen survey resulting in a total of 906 completed questionnaires represents the initial starting point of this study. 
With regard to the first research question, concerning which services are of particular relevance to citizens within the SC context, interesting and at the same time differentiated findings can be derived on the basis of the survey results.

When looking at the four superordinate SC administrative units, it is first to be emphasized that the citizens do not consider any single unit respectively the SC services concerned to be of low or even very low relevance. However, the administrative units of "Smart Social Services" and "Smart Mobility \& Smart Infrastructure" tend to be highly relevant for citizens and thus outperform the units of "Smart Resources \& Smart Environment" and "Smart Governance \& E-Government", which are only rated as medium relevant.

In addition to this top-down view, the more nuanced view at the level of the 14 SC service domains also reveals that the citizens' opinions on the importance of the SC service groups differ greatly in some cases. For example, services relating to a smart economy are considered to be around 20 percent less relevant on average than services relating to the smart development of broadband infrastructure. In view of usually limited resources for the planning and further development of a SC, a citizen-oriented design and ongoing refinement is required due to the high relevance for the citizens especially with regard to the first five to seven SC service domains (cf. Figure 4).

In response to the second research question, 10 public officials from the same municipality were asked about their opinion concerning the relevance of SC services, since to the best of our knowledge there are only very few studies that compare the service preferences of citizens on a broad scale with the estimations of responsible SC executives.

Contrasting the relevance ratings reveals some striking differences in the assessments regarding the importance of SC services, both at the level of the superordinate administrative units and at the level of the dedicated SC service domains (cf. Figure 5 and Fig. 6). Assessments of the "Smart Mobility \& Smart Infrastructure" administrative unit, which is considered to be important by citizens, differ quite significantly on the basis of a differentiated analysis of the dedicated individual services, while the discrepancy regarding the "Smart Governance \& E-Government" unit is even more significant. Moreover, in about 80 percent of all cases, public officials consider their SC services to be more important than can be confirmed by comparing them with citizens' assessments (cf. Figure 7). The differences in preferences and importance ratings, some of which are even more pronounced within the dedicated SC service domains, support the need for extensive communication and adaptation work to better understand citizens' expectations and to adjust the service portfolio accordingly.

All in all, the following three central contributions can be derived from the surveys conducted. First, with regard to the citizen preferences of SC services, it can be stated that prior research findings can be confirmed with the help of the survey results. For instance, the results of the study at hand widely correspond with those of the study by Ji et al. (2021), as citizens generally acknowledge the relevance and importance of various SC services. Furthermore, the findings can be confirmed insofar as SC services such as smart mobility and smart transportation as well as smart infrastructures are attributed a heightened relevance. However, there are also 
some differences existing. In the study at hand, sociocultural SC services are rated as highly relevant, which on the one hand partially confirms the findings of previous studies (Lytras et al., 2019), but on the other hand deviates from the results of other citizen surveys (Ji et al., 2021). The complexity and necessity of respecting preferences along different groups of citizens, already formulated in the literature, can thus be reaffirmed (Abella et al., 2019; Woetzel et al., 2018).

Second, the valuation differences in terms of relevance between citizens and public officials identified within the present study testify the validity of the research community's assumption that a comprehensive coordination and alignment of different stakeholder and, in particular, citizen preferences is yet to be done (Kitchin, 2015; Shelton \& Lodato, 2019). The findings from the study also underscore the opinion, which is already becoming increasingly widespread among public officials as well, that comprehensive public engagement requires an intensified level of dialog-oriented SC solutions and citizen-oriented SC services (Bjørner, 2021). While general differences in perception between citizens and public officials have already been revealed in other municipalities, a cross-comparison additionally confirms that public officials assess the area of smart governance as especially relevant (Bjørner, 2021) or more relevant (Vidiasova \& Cronemberger, 2020), both in isolation and in relation to citizens' assessment.

And third, the insights gained from the study indicate for both science and practice in which SC service areas promising avenues for further exploration and improvement can be found. It offers scholars the opportunity to build on the results of the study and examine in more detail both citizen preferences and evaluation differences with public officials regarding SC services. This can be done either in similar SC contexts for German municipalities or in the form of a comparative study related to an international SC project. Given that preferences are influenced by local conditions, such as geographic, socio-economic as well as cultural factors (Wirtz et al., 2021), this study may provide a suitable basis for matching SC service preferences from other cultural regions and countries. Practitioners, in turn, can use the results of the study as a basis for designing SC services to be more citizen-oriented overall in the future or, if resources are scarce, to prioritize them according to the citizen preferences outlined. As a result of this, the potential added value of smart city management can be realized through increased citizen participation and engagement (Oliveira et al., 2020; Zubizarreta et al., 2016).

Notwithstanding the fact that the design and execution of the study closely followed accepted theoretical principles and, on the basis of these, it is able to provide valuable insights into SC service preferences, it is not free of limitations. In view of city diversity and the factors already mentioned that may affect citizens SC service preferences, the results are only to a certain extent transferable to other SC contexts. A further limitation of the study is that the data collection of the public officials is a relative small number. This allows only a limited number of conclusions. Another limitation is the collection of data in a national language area. The transferability to other countries needs to be examined in this context.

Altogether, regardless of the limitations mentioned above, this study reveals that, in the context of SC design, all the service areas investigated are in principle of importance and can thus make a contribution to success. However, the SC services 


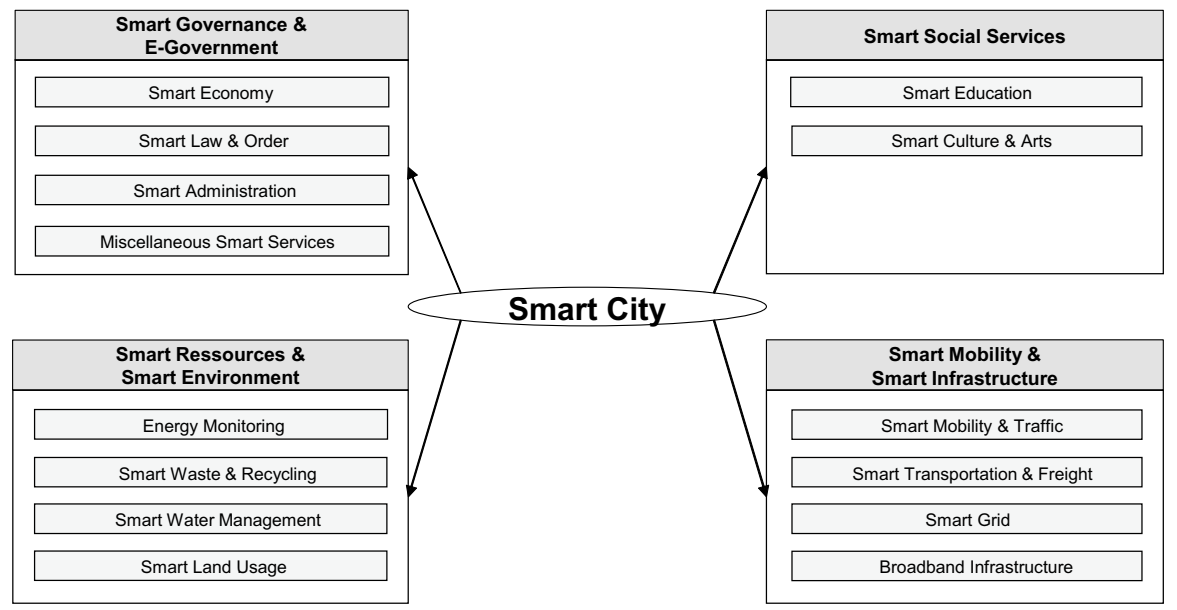

Fig. 8 Assignment of SC service domains to SC administrative units

from the areas of smart culture and education as well as smart mobility and infrastructures require a separate focus due to their increased relevance from the citizens' perspective. In response to the weak citizen orientation identified in this study, future SC design will require additional comprehensive qualitative and quantitative surveys to align the preferences of different stakeholders and maximize the overall success of the SC.

\section{Appendix 1}

\section{Figure 8}

Funding This research study as a part of the research project "Wissens- und Ideentransfer für Innovation in der Verwaltung" (WITI) was funded by the Research Initiative "Innovative Hochschule" of the German Federal Ministry of Education and Research (Grant No.: 03IHS041A). Open Access funding enabled and organized by Projekt DEAL.

\section{Declarations}

Conflicts of Interest The authors declare no conflicts of interest.

Open Access This article is licensed under a Creative Commons Attribution 4.0 International License, which permits use, sharing, adaptation, distribution and reproduction in any medium or format, as long as you give appropriate credit to the original author(s) and the source, provide a link to the Creative Commons licence, and indicate if changes were made. The images or other third party material in this article are included in the article's Creative Commons licence, unless indicated otherwise in a credit line to the material. If material is not included in the article's Creative Commons licence and your intended use is not permitted by statutory regulation or exceeds the permitted use, you will need to obtain permission directly from the copyright holder. To view a copy of this licence, visit http://creativecommons.org/licen ses/by/4.0/. 


\section{References}

Abella, A., Ortiz-de-Urbina-Criado, M., \& De-Pablos-Heredero, C. (2019). A methodology to design and redesign services in smart cities based on the citizen experience. Information Polity, 24, 183-197. https://doi.org/10.3233/IP-180116

Ahvenniemi, H., Huovila, A., Pinto-Seppä, I., \& Airaksinen, M. (2017). What are the differences between sustainable and smart cities? Cities, 60, 234-245. https://doi.org/10.1016/j.cities.2016.09.009

Albino, V., Berardi, U., \& Dangelico, R. M. (2015). Smart Cities: Definitions, Dimensions, Performance, and Initiatives. Journal of Urban Technology, 22, 3-21. https://doi.org/10.1080/10630732.2014.942092

Angelidou, M. (2015). Smart cities: A conjuncture of four forces. Cities, 47, 95-106. https://doi.org/10. 1016/j.cities.2015.05.004

Anttiroiko, A.-V., Valkama, P., \& Bailey, S. J. (2014). Smart cities in the new service economy: Building platforms for smart services. AI \& SOCIETY, 29, 323-334. https://doi.org/10.1007/s00146-013-0464-0

Biagi, B., Ladu, M. G., \& Meleddu, M. (2018). Urban Quality of Life and Capabilities: An Experimental Study. Ecological Economics, 150, 137-152. https://doi.org/10.1016/j.ecolecon.2018.04.011

Bjørner, T. (2021). The advantages of and barriers to being smart in a smart city: The perceptions of project managers within a smart city cluster project in Greater Copenhagen. Cities, 114, 103187. https://doi. org/10.1016/j.cities.2021.103187

Callegaro, M., Lozar Manfreda, K., \& Vehovar, V. (2015). Web survey methodology. Sage Publications.

Cardullo, P., \& Kitchin, R. (2019). Being a ‘citizen' in the smart city: Up and down the scaffold of smart citizen participation in Dublin, Ireland. GeoJournal, 84, 1-13. https://doi.org/10.1007/s10708-018-9845-8

Chourabi, H., Nam, T., Walker, S., Gil-Garcia, J. R., Mellouli, S., Nahon, K., et al. Understanding Smart Cities: An Integrative Framework. In 2012 45th Hawaii International Conference 04.01.2012 (pp. 22892297). IEEE.

Christensen, L. B., Johnson, B., \& Turner, L. A. (2020). Research methods, design, and analysis. Pearson Education Inc.

Gil-Garcia, J. R., Pardo, T. A., \& Nam, T. (2015). What makes a city smart? Identifying core components and proposing an integrative and comprehensive conceptualization. Information Polity, 20, 61-87. https://doi.org/10.3233/IP-150354

Gohari, S., Baer, D., Nielsen, B. F., Gilcher, E., \& Situmorang, W. Z. (2020). Prevailing Approaches and Practices of Citizen Participation in Smart City Projects: Lessons from Trondheim. Norway. Infrastructures, 5, 36. https://doi.org/10.3390/infrastructures5040036

Groves, R. M., \& Peytcheva, E. (2008). The Impact of Nonresponse Rates on Nonresponse Bias: A MetaAnalysis. Public Opinion Quarterly, 72, 167-189. https://doi.org/10.1093/poq/nfn011

Heaton, J., \& Parlikad, A. K. (2019). A conceptual framework for the alignment of infrastructure assets to citizen requirements within a Smart Cities framework. Cities, 90, 32-41. https://doi.org/10.1016/j.cities. 2019.01.041

Hollands, R. G. (2015). Critical interventions into the corporate smart city. Cambridge Journal of Regions, Economy and Society, 8, 61-77. https://doi.org/10.1093/cjres/rsu011

Ji, T., Chen, J.-H., Wei, H.-H., \& Su, Y.-C. (2021). Towards people-centric smart city development: Investigating the citizens' preferences and perceptions about smart-city services in Taiwan. Sustainable Cities and Society, 67, 102691. https://doi.org/10.1016/j.scs.2020.102691

Johnson, P. A., Robinson, P. J., \& Philpot, S. (2020). Type, tweet, tap, and pass: How smart city technology is creating a transactional citizen. Government Information Quarterly, 37, 101414. https://doi.org/10. 1016/j.giq.2019.101414

Joss, S., Cook, M., \& Dayot, Y. (2017). Smart Cities: Towards a New Citizenship Regime? A Discourse Analysis of the British Smart City Standard. Journal of Urban Technology, 24, 29-49. https://doi.org/ 10.1080/10630732.2017.1336027

Kitchin, R. (2015). Making sense of smart cities: Addressing present shortcomings. Cambridge Journal of Regions, Economy and Society, 8, 131-136. https://doi.org/10.1093/cjres/rsu027

Lamberti, L., Benedetti, M., \& Chen, S. (2014). Benefits sought by citizens and channel attitudes for multichannel payment services: Evidence from Italy. Government Information Quarterly, 31, 596-609. https://doi.org/10.1016/j.giq.2014.03.002

Lytras, M., Visvizi, A., \& Sarirete, A. (2019). Clustering Smart City Services: Perceptions, Expectations. Responses. Sustainability, 11, 1669. https://doi.org/10.3390/su11061669 
Macke, J., Rubim Sarate, J. A., \& de Atayde Moschen, S. (2019). Smart sustainable cities evaluation and sense of community. Journal of Cleaner Production, 239, 118103. https://doi.org/10.1016/j.jclepro. 2019.118103

Marrone, M., \& Hammerle, M. (2018). Smart Cities: A Review and Analysis of Stakeholders' Literature. Business \& Information Systems Engineering, 60, 197-213. https://doi.org/10.1007/s12599-018-0535-3

Mora, L., Bolici, R., \& Deakin, M. (2017). The First Two Decades of Smart-City Research: A Bibliometric Analysis. Journal of Urban Technology, 24, 3-27. https://doi.org/10.1080/10630732.2017.1285123

Neirotti, P., de Marco, A., Cagliano, A. C., Mangano, G., \& Scorrano, F. (2014). Current trends in Smart City initiatives: Some stylised facts. Cities, 38, 25-36. https://doi.org/10.1016/j.cities.2013.12.010

Oliveira, T. A., Oliver, M., \& Ramalhinho, H. (2020). Challenges for Connecting Citizens and Smart Cities: ICT. E-Governance and Blockchain. Sustainability, 12, 2926. https://doi.org/10.3390/su12072926

Patton, M. Q. (2015). Qualitative research \& evaluation methods (4th ed., Qualitative evaluation methods). Los Angeles: Sage Publications.

Pereira, G. V., Parycek, P., Falco, E., \& Kleinhans, R. (2018). Smart governance in the context of smart cities: A literature review. Information Polity, 23, 143-162. https://doi.org/10.3233/IP-170067

Shelton, T., \& Lodato, T. (2019). Actually existing smart citizens. City, 23, 35-52. https://doi.org/10.1080/ 13604813.2019.1575115

Simonofski, A., Vallé, T., Serral, E., \& Wautelet, Y. (2021). Investigating context factors in citizen participation strategies: A comparative analysis of Swedish and Belgian smart cities. International Journal of Information Management, 56, 102011. https://doi.org/10.1016/j.ijinfomgt.2019.09.007

Ullah, Z., Al-Turjman, F., Mostarda, L., \& Gagliardi, R. (2020). Applications of Artificial Intelligence and Machine learning in smart cities. Computer Communications, 154, 313-323. https://doi.org/10.1016/j. comcom.2020.02.069

Vanolo, A. (2016). Is there anybody out there? The place and role of citizens in tomorrow's smart cities. Futures, 82, 26-36. https://doi.org/10.1016/j.futures.2016.05.010

Vidiasova, L., \& Cronemberger, F. (2020). Discrepancies in perceptions of smart city initiatives in Saint Petersburg. Russia. Sustainable Cities and Society, 59, 102158. https://doi.org/10.1016/j.scs.2020. 102158

Vidiasova, L., Cronemberger, F., \& Tensina, I. (2018). The Smart City Agenda and the Citizens: Perceptions from the St. Petersburg Experience. In D. A. Alexandrov, A. V. Boukhanovsky, A. V. Chugunov, Y. Kabanov, \& O. Koltsova (Eds.), Digital Transformation and Global Society (Vol. 858, pp. 243-254, Communications in Computer and Information Science). Cham: Springer International Publishing.

von Hippel, E. (1986). Lead Users: A Source of Novel Product Concepts. Management Science, 32, 791805. https://doi.org/10.1287/mnsc.32.7.791

Wirtz, B. W., Müller, W. M., \& Schmidt, F. (2020). Public Smart Service Provision in Smart Cities: A CaseStudy-Based Approach. International Journal of Public Administration, 43, 499-516. https://doi.org/ 10.1080/01900692.2019.1636395

Wirtz, B. W., Müller, W. M., \& Schmidt, F. W. (2021). Digital Public Services in Smart Cities - an Empirical Analysis of Lead User Preferences. Public Organization Review, 21, 299-315. https://doi.org/10.1007/ s11115-020-00492-3

Wirtz, B. W., Weyerer, J. C., \& Schichtel, F. T. (2019). An integrative public IoT framework for smart government. Government Information Quarterly, 36, 333-345. https://doi.org/10.1016/j.giq.2018.07.001

Woetzel, J., Remes, J., Boland, B., Lv, K., Sinha, S., Strube, G., et al. (2018). Smart cities: Digital solutions for a more livable future: Executive summary. https://www.mckinsey.com/ /media/McKinsey/Industries/ Public\%20and\%20Social\%20Sector/Our\%20Insights/Smart\%20cities\%20Digital\%20solutions\%20for\% 20a\%20more\%20livable\%20future/MGI-Smart-Cities-Executive-summary.pdf. Accessed 21 June 2021.

Yigitcanlar, T., Kankanamge, N., \& Vella, K. (2021). How Are Smart City Concepts and Technologies Perceived and Utilized? A Systematic Geo-Twitter Analysis of Smart Cities in Australia. Journal of Urban Technology, 28, 135-154. https://doi.org/10.1080/10630732.2020.1753483

Zikmund, W. G., Babin, B. J., Carr, J. C., \& Carr. (2013). Business Research Methods (with Qualtrics Printed Access Card) (9th ed.). Cengage Learning US.

Zubizarreta, I., Seravalli, A., \& Arrizabalaga, S. (2016). Smart City Concept: What It Is and What It Should Be. Journal of Urban Planning and Development, 142, 4015005. https://doi.org/10.1061/(ASCE)UP. 1943-5444.0000282

Publisher's note Springer Nature remains neutral with regard to jurisdictional claims in published maps and institutional affiliations. 